\title{
First record of multi-species synchronous coral spawning from Malaysia
}

Alvin J Cheliah, Halimi Bin Amir, Julian Hyde, Katie Yewdall, Peter D Steinberg, James R Guest

Knowledge about the timing and synchrony of coral spawning has important implications for both the ecology and management of coral reef ecosystems. Data on the timing of spawning and extent of synchrony, however, are still lacking for many coral reefs, particularly from equatorial regions and from locations within the coral triangle. Here we present the first documentation of a multi-species coral spawning event from reefs around Pulau Tioman, Peninsular Malaysia, a popular diving and tourist destination located on the edge of the coral triangle. At least 8 coral species from 3 genera (Acropora, Montipora and Porites) participated in multi-species spawning over five nights in April 2014, between two nights before and two nights after the full moon. In addition, two Acropora species were witnessed spawning one night prior to the full moon in October 2014. While two of the Acropora species that reproduced in April ( $A$. millepora and $A$. nasuta) exhibited highly synchronous spawning ( $100 \%$ of sampled colonies), two other common species ( $A$. hyacinthus and $A$. digitifera) did not contain visible eggs in the majority of colonies sampled (i.e., $<15 \%$ of colonies) in either April or October, suggesting that these species spawn at other times of the year.To the best of our knowledge, this is the first detailed documented observation of multi-species coral spawning from reefs in Malaysia. These data provide further support for the contention that this phenomenon is a feature of all speciose coral assemblages, including equatorial reefs. More research is needed, however, to determine the seasonal cycles and extent of spawning synchrony on these reefs and elsewhere in Malaysia. 
2 Alvin Chelliah ${ }^{1}$, Halimi Bin Amar ${ }^{1}$, Julian Hyde ${ }^{1}$, Katie Yewdall ${ }^{2}$, Peter D. Steinberg ${ }^{3,4,5}$, James R.

3 Guest $^{3,4 *}$

4

$5 *$ Corresponding author: 40 Jalan Anjung 5, Horizon Hills, Nusajaya, Johor 79100, Malaysia, email

6 jrguest@gmail.com

$8 \quad{ }^{1}$ Reef Check Malaysia, Jalan Ampang, 50450 Kuala Lumpur, Malaysia

$12{ }^{3}$ Centre for Marine Bio-Innovation, School of Biological, Earth and Environmental Sciences,

13 University of New South Wales, Sydney, NSW 2052, Australia

$15{ }^{4}$ Advanced Environmental Biotechnology Centre, Nanyang Environment and Water Research Institute,

16 Nanyang Technological University, Singapore 637141

17

18 5Sydney Institute of Marine Science, Mosman, NSW 2088, Australia 
Introduction

22 Knowledge about the timing and synchrony of coral spawning has important implications for both the

23 ecology and management of coral reef ecosystems (Guest, 2008). The majority of scleractinian corals

24 (i.e., $>60 \%$ of species) are hermaphrodites that broadcast gametes for external fertilization (Baird et al.,

25 2009). Broadcast spawning usually occurs annually and can be highly synchronised within populations

26 (Harrison \& Wallace, 1990). In addition, within diverse coral assemblages there is often considerable

27 overlap in spawning times among species, leading to extensive multi-species spawning events

28 involving numerous taxa (Babcock et al., 1986). For years it was thought that these remarkable

29 reproductive events were restricted to geographical regions that experience large annual fluctuations in

30 temperature and irradiance (Oliver et al., 1988). More recent research from a wide range of locations,

31 however, has revealed that multi-species coral spawning is likely to be a feature of all speciose coral

32 assemblages (Guest et al., 2005a, Baird et al., 2009, Bouwmeester et al., 2015). A plausible

33 explanation for ubiquitous multi-species spawning can be summarized as follows: Spawning synchrony

34 within broadcast spawning species, driven by external environmental timing cues, is likely to be highly

35 adaptive as it increases the chances of cross fertilization (Babcock et al., 1986; Oliver \& Babcock

36 1992). Sympatric coral species are likely to respond independently but in a similar manner to the

37 available timing cues - which will lead to overlap in spawning times among species in speciose

38 assemblages (Oliver et al., 1988). Considering that seasonal timing cues (e.g., sea temperature and

39 irradiance) are features of all coastal locations (even at the equator) (Guest et al., 2005a), multi-species

40 spawning is also likely to be a feature of all speciose coral assemblages.

41 Despite recent advances in knowledge from several previously understudied locations (e.g.,

42 Vicentuan et al., 2008, Permata et al., 2012), data on spawning timing and extent of synchrony are still

43 lacking for many coral reefs, particularly from locations within the coral triangle, an area of 
44 exceptionally high species diversity encompassing Malaysia, Indonesia, the Philippines and New

45 Guinea (Hoeksema, 2007). The east coast of Peninsular Malaysia has almost 400 recorded scleractinian

46 species, around $70 \%$ of species recorded from the entire coral triangle (Huang et al., 2014), and is

47 therefore an area of considerable global importance in terms of marine biodiversity (Harborne et al.,

48 2000). Here we present the first documentation of a multi-species coral spawning event from reefs

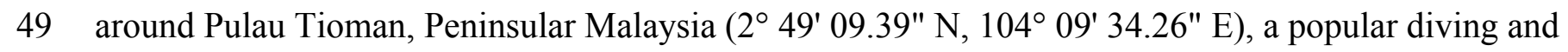

50 tourist destination located on the edge of the coral triangle.

52 Materials and methods

54 Evidence from reefs within the coral triangle suggest two coral spawning peaks in March/April and

55 October/November, typically with a minor and a major spawning season for each location (Baird et al.,

56 2009). The spawning times of coral species at sites around Pulau Tioman were examined using three

57 different methods. Firstly, corals were sampled at two fringing reef sites on the west coast of Tioman

58 (TDC House Reef: $2^{\circ} 48^{\prime} 56.47^{\prime \prime} \mathrm{N} 104^{\circ} 09^{\prime} 05.66^{\prime \prime} \mathrm{E}$ and; Tumuk: $2^{\circ} 47^{\prime} 32.80^{\prime \prime} \mathrm{N} 104^{\circ} 07^{\prime} 22.02^{\prime \prime} \mathrm{E}$ )

59 on April 122014 (3 days before the full moon) and on October 72014 (1 day before full moon) to

60 establish the extent of population synchrony within selected coral populations of Acropora. Sampling

61 was done by removing up to three branches from randomly selected, independent (i.e., $>5$ meters

62 apart), replicate colonies of Acropora millepora, A. nasuta, A. hyacinthus and A. digitifera (Table 1)

63 (following Baird et al., 2002). Only Acropora colonies $>30 \mathrm{~cm}$ diameter were sampled to ensure that

64 all were of sufficient size and age to be reproductively mature (see Baria et al., 2012; Wallace 1985).

65 A. millepora, and A. nasuta were only sampled in April whereas A. hyacinthus, A. digitifera were

66 sampled in April and October. For each colony, the presence or absence of visible pigmented or white

67 eggs was noted in situ by a snorkeler. The presence of pigmented oocytes is indicative of spawning on 
68 or close to the date of the next full moon, whereas the presence of visible white eggs indicates that

69 colony will spawn within the next two to three months. Empty colonies have either recently spawned

70 or will not spawn for at least three months (Baird et al., 2002). Secondly, to establish the night and time

71 of spawning and the extent of spawning synchrony, we placed small egg-sperm bundle traps made

72 from the bases of upturned plastic water bottles (Guest et al., 2010) over 12 gravid colonies of $A$.

73 millepora and eight of A. nasuta on 12 April 2014 at TDC House Reef. Gamete traps were also placed

74 over 2 colonies of $A$. digitifera and, in addition, 2 colonies of $A$. tenuis that were found to contain

75 pigmented eggs on 7 October 2014. Traps were checked each morning for the presence or absence of

76 released gametes until all colonies had spawned. Finally, in situ observations were made at TDC House

77 Reef by snorkelers on the nights of 13 to 17 April 2014 and on 8 and 9 October 2014 between the

78 hours of 1900 and 2300 to document spawning (approx. $28 \mathrm{~h}$ of in situ observation time in total).

79 While the main aim of the direct observations was to establish the timing of spawning of the tagged

80 Acropora colonies, a note was also made of any other coral species spawning during the observation

81 period to assess the extent multi-species spawning at this site.

82

83 Results and Discussion

85 All sampled colonies of $A$. millepora and A. nasuta contained visible pigmented eggs when sampled on

8612 April 2014 (Table 1). In contrast all sampled colonies of A. digitifera were empty of eggs in April

87 and only $5 \%$ of $A$. hyacinthus colonies contained pigmented eggs in April with the remainder of the

88 sampled colonies being empty (Table 1). In October, all A. hyacinthus colonies were empty whereas

$8914 \%$ of $A$. digitifera colonies contained pigmented eggs (Table 1). Examination of the gamete traps

90 showed that 2 colonies (17\%) of A. millepora colonies spawned on 13 April, while the remaining

91 tagged colonies of both A. millepora and A. nasuta spawned on 14 April (one night before the full 
92 moon)(Fig. 1, Table 2). Similarly, on October 8, egg-sperm bundles were found in gamete traps placed

93 over two tagged colonies each of $A$. tenuis and A. digitifera, indicating spawning on October 7 (one

94 night before full moon) for these species. Coral spawning was observed in situ on four of the five

95 nights of observation in April (13,14,16 and 17 April) between the hours of 2030 and 2225. No corals

96 were observed spawning on April 15. At least 8 species from 3 genera (Acropora, Montipora and

97 Porites) and 2 families participated in the spawning event (Fig. 1, Table 2). Night time observations

98 were carried out on October 8 and 9, but no spawning was witnessed directly on these nights. To the

99 best of our knowledge, this is the first detailed documented observation of multi-species coral

100 spawning from reefs in Malaysia. Our data, therefore, support the contention that this phenomenon is a

101 feature of all speciose coral assemblages, including those on equatorial reefs (Baird \& Guest, 2009;

102 Guest et al., 2005a). The number of species observed to participate in these events is relatively modest

103 compared to spawning events seen elsewhere (e.g., Babcock et al., 1986). Considering, however, that

104 Pulau Tioman has at least 180 known coral species (Harborne et al., 2000) and that observations were

105 only carried out at one site by two or three observers, it is likely that more extensive surveys will reveal

106 other species participating in these multi-species spawning events.

While two species of Acropora (A. millepora and A. nasuta) exhibited highly synchronous

108 spawning in April, two other common species (A. hyacinthus and A. digitifera) did not contain visible

109 eggs in the majority of colonies sampled in either April or October, suggesting spawning at other times

110 of the year for these species. While evidence from nearby locations suggest that March/April and

111 October/November are the two main spawning peaks for this biogeographic region (Baird et al., 2009)

112 extended spawning lasting several months are common on many Indo-Pacific coral reefs (e.g.,

113 Bouwmeester et al., 2015). The seasonal timing of spawning (i.e., March/April) for A. millepora and A.

114 nasuta is consistent with observations of spawning seasonality for Acropora species from other

115 locations in Southeast Asia (e.g., Singapore, north-western Philippines, Indonesia)(Guest et al., 2002, 
116 Vicentuan et al., 2008, Permata et al., 2012). Seasonal spawning timing within and among coral species

117 is often consistent over broad geographical ranges because individuals are likely to respond in a similar

118 way to environmental timing cues (e.g., sea surface temperature, irradiance) (Willis et al., 1985; van

119 Woesik et al., 2006). The fact, therefore, that A. hyacinthus and A. digitifera did not spawn at this time

120 in Pulau Tioman is surprising as these species have been observed to spawn during the major multi-

121 species spawning period in April in nearby Singapore (Guest et al., 2005a) and Bintan, Indonesia

122 (unpublished data). All sampled colonies were $>30 \mathrm{~cm}$ in diameter and were found in the same habitat,

123 thus ruling out the possibility that sampled colonies were reproductively immature. It is also interesting

124 to note that the lunar timing of spawning is earlier in Pulau Tioman than for conspecifics in Singapore.

125 For example most species in Singapore spawn between 3 and 6 nights after the full moon (Guest et al.,

126 2002, 2005b) whereas in Pulau Tioman corals spawned between 2 nights before and 2 nights after the

127 full moon.

128 Clearly, more research is needed to determine the timing and extent of coral spawning

129 synchrony on these reefs and elsewhere in Malaysia. In particular, year round sampling is required to

130 establish reproductive phenologies for a range of species to determine the cause of timing differences

131 within conspecifics among locations. Comparisons of spawning timing among reefs between the east

132 and west coasts of Peninsular Malaysia are of particular interest as they experience contrasting

133 monsoon seasons and environmental conditions (Toda et al., 2007).

135 Acknowledgements

137 We are very grateful to the staff at Tioman Dive Centre for field support. All research work was carried

138 out under a memorandum of understanding between Reef Check Malaysia and the Department of

139 Marine Parks Malaysia. 


\section{References}

143 Babcock RC, Bull GD, Harrison PL, Heyward AJ, Oliver JK, Wallace CC, Willis BL 1986.

144 Synchronous spawnings of 105 scleractinian coral species on the Great Barrier Reef. Marine 145 Biology 90: 379-394. DOI: 10.1007/BF00428562.

146

147 Baird AH, Guest JR 2009. Spawning synchrony in scleractinian corals: comment on Mangubhai \& 148 Harrison (2008). Marine Ecology Progress Series 374: 301-304. DOI: 10.3354/meps07838.

Baird AH, Marshall PA, Wolstenholme J 2002. Latitudinal variation in the reproduction of Acropora in

151 the Coral Sea. In Proceedings of the 9th International Coral Reef Symposium 1: 385-389.

152

153 Baird AH, Guest JR, Willis BL 2009. Systematic and biogeographical patterns in the reproductive

154 biology of scleractinian corals. Annual Review of Ecology, Evolution, and Systematics 40: 551-571.

155 DOI: 10.1146/annurev.ecolsys.110308.120220.

156

157 Baria MVB, de la Cruz DW, Villanueva RD, Guest JR 2012. Spawning of three-year-old Acropora 158 millepora corals reared from larvae in northwestern Philippines. Bulletin of Marine Science 88: 61-62.

160 Bouwmeester J, Baird AH, Chen CJ, Guest JR, Vicentuan KC, Berumen ML 2015. Multi-species

161 spawning synchrony within scleractinian coral assemblages in the Red Sea. Coral Reefs DOI:

162 10.1007/s00338-014-1214-6. 
164 Guest J 2008. Ecology. How reefs respond to mass coral spawning. Science 320:(5876) 621-623.

165 DOI: $10.1126 /$ science. 1155285.

166

167 Guest JR, Baird AH, Goh BPL, Chou LM 2002. Multispecific, synchronous coral spawning in

168 Singapore. Coral Reefs, 21: 422-423. DOI: 10.1007/s00338-002-0263-4.

169

170 Guest JR, Baird AH, Goh BPL, Chou LM 2005a. Seasonal reproduction in equatorial reef

171 corals. Invertebrate Reproduction \& Development 48: 207-218. DOI:

$172 \quad 10.1080 / 07924259.2005 .9652186$.

173

174 Guest JR, Baird AH, Goh BPL, Chou LM 2005b. Reproductive seasonality in an equatorial assemblage

175 of scleractinian corals. Coral Reefs 24: 112-116. DOI: 10.1007/s00338-004-0433-7.

176

177 Guest JR, Heyward A, Omori M, Iwao K, Morse A, Boch C 2010. Rearing coral larvae for reef

178 rehabilitation. In: Edwards AJ (ed) Reef rehabilitation manual. Coral Reef Targeted Research \&

179 Capacity Building for Management Program: St. Lucia, Australia pp. 73-98.

180

181 Harborne A, Fenner D, Barnes A, Beger M, Harding S, Roxburgh T 2000. Status report on the coral

182 reefs of the east coast of Peninsula Malaysia. Report Prepared to Department of Fisheries Malaysia,

183 Kuala Lumpur, Malaysia pp 88.

184

185 Harrison PL, Wallace CC 1990. Reproduction, dispersal and recruitment of scleractinian corals. In:

186 Ecosystems of the world. Elsevier, Amsterdam 25: 133-207. 
188 Hoeksema BW 2007. Delineation of the Indo-Malayan centre of maximum marine biodiversity: the

189 Coral Triangle. In: Biogeography, time, and place: distributions, barriers, and islands. Springer,

190 Netherlands 29: 117-178. DOI: 10.1007/978-1-4020-6374-9_5.

191

192 Huang D, Licuanan WY, Hoeksema BW, Chen CA, Put AO, Huang H, Lane DJW, Vo ST, Waheed Z,

193 Yang Amri A, Yeemin T, Chou LM 2014. Extraordinary diversity of reef corals in the South China

194 Sea. Marine Biodiversity DOI 10.1007/s12526-014-0236-1.

195

196 Oliver JK, Babcock RC, Harrison PL, Willis BL 1988. Geographic extent of mass coral spawning:

197 clues to ultimate causal factors. In: Proceedings of the 6th International Coral Reef Symposium 2: 803198810.

199

200 Oliver JK, Babcock RC 1992. Aspects of the fertilization ecology of broadcast spawning corals: sperm

201 dilution effects and in situ measurements of fertilization. Biological Bulletin 183: 409-417.

202

203 Permata D, Indrayanti E, Haryanti D, Fika L, Arfiyan H, Achmad A 2012. Biannual multispecific

204 spawning in Karimunjawa Archipelago, Indonesia. Coral Reefs 31: 907. DOI: 10.1007/s00338-012-

$205 \quad 0909-9$.

206

207 Toda T, Tomoko O, Takeshi M, Alfian BAAK, Rajuddin MKM, Ryota N, Chen W, Kunio T. T,

208 Othman BHR, Makoto T 2007. Community structures of coral reefs around Peninsular Malaysia.

209 Journal of Oceanography 63: 113-123. DOI: 10.1007/s10872-007-0009-6. 
211 Van Woesik R, Lacharmoise F, Köksal S 2006. Annual cycles of solar insolation predict spawning

212 times of Caribbean corals. Ecology Letters 9: 390-398.

213

214 Vicentuan KC, Guest JR, Baria MV, Cabaitan PC, Dizon RM, Villanueva RD, Aliño PM, Edwards AJ, 215 Gomez ED, Heyward AJ 2008. Multi-species spawning of corals in north-western Philippines. Coral 216 Reefs 27: 83-83. DOI: 10.1007/s00338-007-0325-8.

217

218 Wallace CC 1985. Reproduction, recruitment and fragmentation in nine sympatric species of the coral 219 genus Acropora. Marine Biology 88: 217-233.

220

221 Willis BL, Babcock RC, Harrison PL, Oliver JK, Wallace CC 1985. Patterns in the mass spawning of 222 corals on the Great Barrier Reef from 1981 to 1984. Proceedings of the Fifth International Coral Reef 223 Congress, Tahiti 4: 343-348. 
Table $\mathbf{1}$ (on next page)

Proportion of colonies sampled containing visible eggs.

Table 1. Proportion of population with pigmented eggs, white eggs and/or empty colonies in April and October 2014. 


\section{PeerJ Reviewing Manuscript}

\begin{tabular}{llcccc}
\hline Species & Date & Pigmented (\%) & White (\%) & Empty (\%) & $\mathrm{n}$ \\
\hline Acropora millepora & $12 / 04 / 2014$ & 100 & 0 & 0 & 26 \\
Acropora nasuta & $12 / 04 / 2014$ & 100 & 0 & 0 & 17 \\
Acropora digitifera & $12 / 04 / 2014$ & 0 & 0 & 100 & 20 \\
& $7 / 10 / 2014$ & 14 & 0 & 0 & 15 \\
Acropora hyacinthus & $12 / 04 / 2014$ & 5 & 0 & 0 & 20 \\
& $7 / 10 / 2014$ & 0 & 0 & 100 & 15 \\
\hline
\end{tabular}


1

Multi species coral spawning in Pulau Tioman

Fig. 1. Images of coral spawning in Pulau Tioman showing: a) a gamete trap containing eggsperm bundles on Acropora digitifera, b) spawning of Montipora sp. 1, c) A. millepora, d) Porites sp. 2, e) A. humilis, f) and a gamete slick on the surface immediately after spawning. 


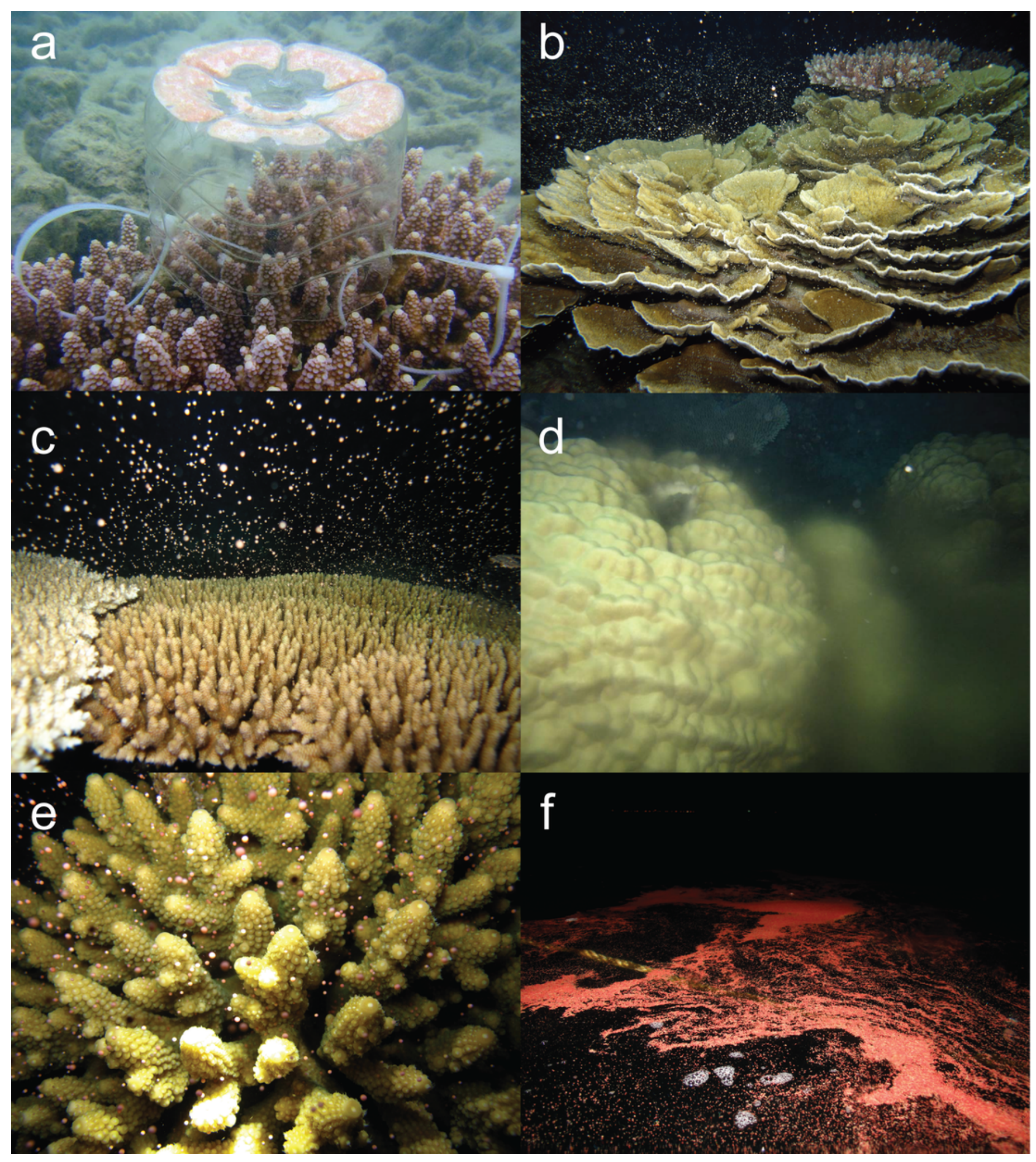


Table 2 (on next page)

Species participation and timing of spawning during multi-species spawning in Pulau Tioman.

Table 2. Species participation during a multi-species spawning event in April 2014. Spawning nights are relative to date of full moon in 2014 (April 15). Type of gamete release: $B=$ eggsperm bundles, $\mathrm{S}=$ sperm. 


\section{PeerJ Reviewing Manuscript}

\begin{tabular}{clccc}
\hline Family & \multicolumn{1}{c}{ Species } & Spawning & Spawning time & Gametes \\
& & nights & \\
& & & released \\
\hline Acroporidae & Acropora millepora & -2 to -1 & 2115 to 2200 & B \\
& Acropora nasuta & -1 & 2115 to 2200 & B \\
& Acropora humilis & -1 & 2115 to 2200 & B \\
& Acropora valida & -1 & 2115 to 2200 & B \\
& Montipora sp. 1 & +1 to +2 & 2030 to 2225 & B \\
& Montipora sp. 2 & +2 & 2030 to 2225 & B \\
Poritidae & Porites sp. 1 & +1 to +2 & 2030 to 2225 & S \\
& Porites sp. 2 & +1 & 2115 to 2225 & S \\
\hline
\end{tabular}

